\title{
"Managing through Failure": More than an Oxymoron?
}

\author{
"A failure is one who has blundered but failed to exploit the experience" \\ - Elbert Hubbard \\ David Strutton, Ph.D. \\ Professor of Marketing and Logistics \\ Department of Marketing \& Logistics \\ University of North Texas \\ Denton, TX 76205, USA
}

Tel: 1-940-565-3123Ｅ-mail: Strutton@unt.edu

Received: August 4, 2012

doi:10.5430/bmr.v1n3p37
Accepted: August 15, 2012

Online Published: August 20, 2012

URL: http://dx.doi.org/10.5430/bmr.v1n3p37

\begin{abstract}
In a "man-bites-dog" inversion of principles more likely to be employed in leadership primers (i.e., that failure is somehow not an option), this paper suggests managers should embrace the possibility that they as well as their subordinates inevitably will at least occasionally fail. Their acceptance suggests managers should learn more about certain historical perspectives and principles from which the ongoing need to lead subordinates through inescapable failure could be addressed more effectively. Below, ten ironic observations and three overarching historically grounded principles are identified, justified and explicated. Each prescriptive point is designed and fit-together in ways intended to assist modern managers in their efforts to lead subordinates and themselves though failure.
\end{abstract}

Keywords: Failure, Managing Failure, Irony, Oxymoron, Successful Leadership

\section{Introduction}

Failure is not an option.

Most managers are probably familiar with the adage. Many surely agree with the never-say-die premise that anchors it. Once, I passionately believed "failure was not an option." At the time, I was battling leukemia and had committed to bone marrow transplantation (hereafter, BMT). This frequently deadly treatment was the only option available in the medical community's arsenal that offered hope for a cure.

Entering Seattle's transplant unit, only two outcomes were possible. The treatment would destroy my cancer - or me. And if I died, death would arrive many months before leukemia would have had its final say. While I understood this, the prospect of failure was so onerous that its possibility was banished. Such was my mind's ability to rationalize and explain away the possibility and consequences of failure. Are most managers similarly capable of explaining away and thus more coping effectively with - the consequences of failure?

Prior to their decisions to transplant, similar rationalizations likely emboldened the two patients being treated in the rooms adjacent to mine. But soon after my arrival, each died, but not from their cancer. Instead, each died after treatment began because he had voluntarily entered "bone marrow transplantation's healing hell" (Groopman 1998, p. 34). Each died - each failed - because when cancer treatment involves marrow transplantation, failure frequently occurs. Similarly, failure is inevitable within all business settings. No one makes the right decision every time; products and new hires do fail; opportunities are missed.

Failure hurts. It discourages. But failure will arise. Managers should learn more about managing through the failure that inevitably arises within the firms and among the people they lead.

\section{Accepting the Possibility of Failure}

Each of my fellow patients who died in the transplant unit likely would have lived pain-free for perhaps a year had he not undergone BMT. Yet each voluntarily opted for transplant. Each man began treatment after having made a 
decision that, if successful, promised a longer cancer-free life. Conversely, treatment failure promised a far quicker and more painful death. Failure? For all three of us, failure was definitely not an option.

Rationalizing away the prospect of failure proved easy for me. After all, the context was cancer, and failure meant death. Consequently, after informing my spouse about preferred funeral arrangements and asset distributions, no longer considering failure as an option made sense. But in most business contexts, failing to account and thus failing to prepare for the prospect of failure is indefensible. That every manager and subordinate will fail, at least occasionally, is simple fact.

Of course, my fellow patients and I understood failure was an option. Signing multiple do-not-resuscitate documents bring odds into sharp focus. But I refused to accept those odds. Consequently, I failed to prepare fully for failure's possibility. Still, my myopically optimistic view - one where failure truly never was viewed an option when in fact it could prove unavoidable - impresses me as the only strategy consistent with sanity when failure would visit absolutely irrecoverable loss upon the decision maker. Of course, such draconian circumstances rarely, if ever, arise in managerial contexts.

Another adage suggests: "Success is never final, and failure never fatal." Plainly, some people, facing certain choices, might reasonably disagree with this adage's closing phrase. Sometimes, failure is final. And in such cases, failure truly may not be a mental option. But that was life. And here, our business is merely managing, while sometimes actually leading, others. Within this context, at-least-occasional-failure of others, as well as our own, clearly is a reasonable expectation, and thus an option for which all should prepare.

\section{Failure's Inescapable Nature}

"To climb great hills requires a slow pace" - William Shakespeare

Absolutely "life or death" consequences rarely ensue from the outcomes of managerial decisions. Managerial decisions are important. But we are still just discussing business. And in business settings, failures and successes often are neither completely negative nor positive. Even long-term contracts or relationships expire or end; but each are subject to being won or lost, again. Employees come and go, for better or worse, but others can be hired. But one absolute attaches absolutely to managerial failure. It is this: Much can be learned and potentially applied from failure's lessons. But that compensatory result will eventuate only if managers learn to experience and respond to failure from the proper perspective.

Mindful of this benefit, this article follows from a presumption that managers typically should benefit from pondering the extent to which failure might occasionally be viewed as an acceptable possibility. Enlightened self-interest alone suggests managers should prepare industriously for its arrival, because failure is more than a possibility. Given time, it will arrive. To prepare for failure's inevitability, managers should learn the proper perspectives from which to encounter and, over time, counter failure.

In a "man-bites-dog" inversion of principles more likely to be employed in leadership primers (i.e., failure is not an option), this paper suggests managers should embrace the possibility that they as well as their subordinates inevitably will fail, at least occasionally. Such acceptance, in turn, suggests managers should learn more about certain historical perspectives and principles from which the need to lead subordinates through inescapable episodes of failure might be effectively managed. Once such perspectives are adapted, managers may discover how lasting and renewable sources of power can ensue from the ability to lead subordinates through the myriad opportunities to fail that unavoidably arise in their professional lives. In sum, those aspiring to true leadership status should learn how to lead as if "failure (Note 1) was very much a possibility.

\section{Re-Framing Failure}

"The only time you don't fail is the last time you try anything, and its works" - William Strong

Baseball games feature an organizational lifelike rhythm. They involve long periods of seeming inactivity, interrupted periodically by abrupt and intricate movements and change. Baseball also features maddeningly unpredictable outcomes - despite managers' ongoing calculations and tactical shifts. Finally, baseball features chronic failure. Mere 30\% success rates (at bat) or 62 defeats (in a season) exemplify excellence. For apparently good reasons, the game is frequently tagged as a metaphor for life. Authors like George Will or Gary Wills couldn't be wrong, could they? Actually, each might be a bit off base.

Arguably, baseball-as-failure might more represent a superior metaphor for managerial life. Most managerial lives are marked by more than occasional failure. (Even successful insurance agencies experience $80+\%$ five-year turnover rates.) And in baseball, life, or management, top prizes are reserved only for a truly fortunate - or especially 
insightful, motivated or gifted - few. Yet even those fortunate, motivated few frequently fail during their ascent to or tenures at the top. Such assertions apply everywhere to everyone. Certainly, they apply to the large majority of the minority who emerge as leaders.

Once managers realize this circumstance as fact, through direct or vicarious experience, they typically respond in one of two ways. The first approach entails slouching into remainder-of-tenure-long sulks that eventually lead to termination-of-tenure-death spirals. The second entails managers pursuing fulfillment outside the precincts of great professional accomplishment. They learn to prize less than ultimate wins leading to nowhere of great significance for themselves or their firms, but that nevertheless have value in themselves and sustain careers. No fault can be attached to this second response. The response embodies the reality known as being average.

Yet a third response exists. Surprisingly few managers exercise it. It entails purposefully striving to learn how best to lead oneself and one's subordinates through failures that will arise inevitably in their respective professional lives.

Failure. When the subject is business, failure is everybody's option. For better or for worse, numbers don't lie. Strategic business units, strategic initiatives and managers themselves either achieve or fail to achieve goals. No middle-ground exists. When organizations reach new heights, success is usually attributed to a few star performers. When organizations fail to meet goals, managerial shortcomings are likely cited.

Consequently, leading successfully despite at least occasional failure is every manager's business, even when subordinates he or she leads may be equally or even more responsible. Apparently, management of failure is also every manager's problem. Stalled or unfilled careers await many managers, unless they learn to react constructively to failures' inevitable appearance. An initial managerial irony becomes apparent. The irony follows from the fact that:

\section{- $\quad$ Too few managers adequately prepare themselves or their followers for failure, despite its inevitability.}

And just as John Wooden taught, "failing to plan is like planning to fail," many managers fail unnecessarily. In no small measure, many fail because of the mistakes of voluntary omission embedded in this managerial irony. Ironically, such managers may fall prey to the short-sighted and mistaken assumption that they should lead as if failure was not always a possibility in the business world.

Irony has been defined as an "outcome of events contrary to what was, or might have been, expected" (Random House Dictionary 2012). Irony can be used to introduce innovative ways of thinking about old issues. Ironic observations can provide new shades of meaning and original ways of responding to old problems. Ironic observations are often humorous, surprising and intriguing. More significantly, here, the ironic observations reported below may prove practically useful to managers in their efforts to lead others through failure.

\section{Applying Lessons from Failure}

"Victory often goes to players making the next-to-last mistake" - Seavielly Grigorievitch Tartakower

How often do managers enjoy absolute control over the myriad factors that influence the success (or failure) of the unit they lead? Most realize managers rarely have absolute control over such factors. Just the same, many managers manage as if they assumed the opposite were true.

Against such a backdrop, it is ironic that:

\section{- Managers are typically held responsible for the failures of their subordinates - even when those failures are not their fault.}

One practical managerial implication emerges from this irony: Managers should realize their individual success in large part depends on the degree to which their subordinates play their parts and perform effectively within whatever roles they have been assigned. Then mangers should respond (i.e., manage) accordingly. Few if any organizations exist that rely exclusively on managerial talent or effort to succeed. Usually, successful management is more a social than individual event.

Once managers realize this, and act accordingly, three useful managerial guidelines emerge. For starters, managers should lead as though they were directly responsible to subordinates, as well as responsible for subordinate's success. Second, managers should lead by pulling subordinates toward themselves, rather than pushing subordinates ahead by themselves. Finally, managers should acknowledge they need to share the way with and as lead the way for the people they manage. Fundamentally, managers should prepare the way for subordinates, but also prepare subordinates for the specific they must travel. 
Such guidelines are not advocated because they are humane, open-minded or politically correct. Instead, they are proposed because managers who adhere to them should function more effectively than those that don't. Why? Because leaders following these guidelines will be able to more effectively lead reports through the inescapable failures that each will encounter.

\section{Historical Lessons: What, Who and Why}

Human needs never change. Regardless of whether the desires are ever satisfied, all humans need to eat, to feel safe, to sense they belong, and to love and be loved. Consequently, the same human frailties and idiosyncrasies always play out in managerial/subordinate relationships regardless of how much it may appear that technology or economic circumstance is somehow mediating the relationship. Volatility - or at least its prospect - always exists in managerial/subordinate relationships. Indeed, suggesting no systematic training capable of producing consistently failure-free managerial-subordinate relationships will likely never exist seems reasonable. But clearly, progressive method through which managers can learn more from and about failure should be pursued. One method follows.

This method for leading successfully others through failure's inescapable emergence is as simple as answering "one, two, three" - questions, that is. Indeed, these questions are simple: "what?", "who?", and "why?" Specifically, the argument below is that the "answers" provided by leaders to these subordinate questions should be uniformly inspiring (What?), unifying (Who?), and persuasive (Why?). Achieve this, and any manager's prospect for leading more successfully through failure should expand.

Insert Figure 1 Here

This question set - who, what, why - already reside inside subordinates' minds, regardless of whether they are asked formally or informally. For managers facing the task of leading employees through failure's often inescapable nature, the importance of effectively answering subordinates' "what", who," and "why" is difficult to overstate. Suggesting only three questions need be answered is simple enough - seemingly, too simple. But advocating that only three succinct questions need be answered by managers is consistent with Einstein's principle that the simplest (rather than the most simplistic) solution to any complicated problem be pursued first.

\subsection{Answering and Learning from "What?"}

Successful management, executed during the prospect or presence of failure, requires learned inventiveness. This suggestion does not imply managers should use tricks, or be anything other than real. Nor does an endorsement for inventiveness suggest managers should be fraudulent - in any sense. Instead, the recommendation implies successful management often requires inventive and, at times, visionary, imagination.

Inventiveness is necessary because accomplished managers often are accomplished because they have produced creative, compelling and galvanizing answers to another core follower question: "What do you (as an individual) or all of you (as a strategic unit) want to achieve?" And when failure looms, invention of imaginative, even visionary, responses to "What?" may prove crucial to managerial success. Most managers' ability to successfully lead subordinates through inescapable failures is rooted in, and a product of, their subordinates' imagination. It follows:

\section{- $\quad$ For managers, the needed solutions, for successful leadership in the face of failure, reside inside the minds of the people they lead.}

Ironically, history suggests many managers routinely ignore the source of power that resides within their subordinates' collective inventiveness. Yet some managers routinely account for and respond to power source like the opportunity that it is. Not coincidentally, those individuals often achieve more than ordinary managerial success.

Learned inventiveness reflects a person's ability to resolve difficulties through resourceful and creative means. Inventiveness embodies the "faculty or action of producing mental images of what is not present or has yet to be experienced" (Random House Dictionary). In corporate settings, imagining what "is not present" or "has yet to be experienced" forces consideration of questions such as "what might be?" (in the future) as well as "what once was, but no longer is?" (during the past). Indeed, both past and present - as each relates to their focal unit - should be evaluated during managerial efforts to answer "What?"

Consequently, two additional approaches exist through which leaders might lead through failure. Each involves efforts aimed at motivating employees to move in one or another direction. In the first, inventive managers might resurrect formerly positive employee activities by eliciting reference to some "golden age" that no longer exists. The golden age may be imagined; perhaps it is mythical. It could be genuine. The difference is irrelevant. Instead what matters is whether the image projected by this golden age sufficiently motivates subordinates. Such inventiveness 
may be leveraged to motivate followers forward from a presumably difficult present toward a future that may prove even more challenging, but that promises worthy rewards in the end - if subsequent tests are successfully passed.

The manner in which cancer survivors experience BMT exemplifies the three-dimensional character of the bad/worse/better case scenario just constructed. For them, the path from cancer victim (a difficult present) to cancer survivor must lead through nasty and unnerving treatments (an even more challenging future) to earn a return to vigorous health (a prior and future golden age). My learned invention of a healthy future similar to an easily recallable healthy past functioned as a failure-proofing motivator to "work" as hard as I could in the present in order to earn the opportunity to die because of something else, rather than cancer, in the future. And the inspirational focus it provided drove me steadily forward during nearly two years of recovery. When an alluring future lies within one's grasp, a "refuse-to-lose" attitude arises far more easily. Under such motivational conditions, an employee's will-to-win should burn brightly indeed, which is, in the end, an outcome highly sought by managers.

In a second managerial approach through which the presumed inescapability of failure could be ameliorated, inventive managers could imagine what "has yet to be experienced" by those they manage. And as a result of this imagining, managers would be better equipped able to furnish employees with a promising, and presumably motivating, vision of a more preferable future. Successful political leaders tread indelibly in constituents imaginations. They constantly produce and then market imaginary - even utopian - visions of other places (where there is "no more war" or "universal healthcare") that literally is "no place" at present. But ideally, such a place could exist one day, particularly if followers follow scripts advocated by the leader.

The notion of learning lessons from historical failure is grounded in managerial reality. Stated plainly, if managers cannot conjure forth superior alternatives to the status quo, why should anyone follow them as the possibility or reality of failure rises? And certainly, it becomes easier to understand why the collective imagination of subordinates represents a compelling source of leadership power once managers consider, ironically, that:

\section{- $\quad$ Most successful managers charged with leading business units produce few tangible results.}

Yet such outcomes are exactly what managers should produce. Managers may recruit, select, train, evaluate, motivate, inspire, and lead subordinates. But rarely do they produce tangible outcomes or achieve final successes completely on their own.

Instead, a primary responsibility of successful managers is to invent visions that motivate followers forward through the prospect of failure toward the presence of success. Ideally, their "purchase" of these visions will enable subordinates led by such managers to more effectively assault new "markets" (acquire power in the future), defend current "markets" (retain power in the present), or surmount past "market" failures (regain power lost in the past). Think back a few years, to the past, present and future of IBM - and each point is amply illustrated. Unfortunately, many leaders fail to function as the inspirationally inventive imaginations of the organizations they lead. As a consequence, their units are less likely to overcome failure.

To apply lessons from history, managers might sketch out visions of idealized futures by drawing from past successes or failures. History perpetually suggests the inventive use of drawing objects - pen, voice, sword or tradition - distinguishes more powerful leaders from also-rans. "Managers" as disparate as corporate CEOs, military officers, or athletic coaches each face similar challenges. And managers from any background are unlikely to lead for long unless they generate persuasive accounts of their team's past (How we get here?), present (Where do we go from here?), and future (What must be done to get there?). Why? Because managers failing to offer these persuasive accounts are less likely to successfully manage failure's inevitable appearance.

To enhance the prospect that they can lead business units through the prospect of failure, managers need only inspire and mobilize a critical unit core. No small order, but manageable. As a precursor to success, team members must interpret manager-initiated events, documents, or conversations as meaning something closely approximating what the leader originally intended. Naturally, managers are more likely to inspire such a core when their vision is just and reasonable, or perceived as just and reasonable, by this unit. Once a sufficiently motivated core force is energized, individual constituents can persuade or coerce other, lagging, members into pursuing or refraining from whatever actions prove necessary to overcome present-tense or future failure. Managers whose inventiveness is rooted in their unit's historical experiences are more likely to manage this task effectively. In a real sense, such persuasive accounts of the past, present and future should resonate with the unit's Zeitgeist - i.e., "time-spirit."

Leaders who ignore the symbiotic nature of the management-subordinate relationship do so at their own risk. A striking example of how such resonance can be achieved is also one of the worst. Adolf Hitler's 1920's speech-making about the "dishonor" of the Treaty of Versailles' (the past) resonated precisely with views held (the 
present) by many ordinary Germans. He proceeded to sell them a vision of a more preferred future, and did so with extreme inventiveness and persuasiveness. By the mid-1930s that dedicated critical core of followers had thrust Hitler toward leadership and the world toward World War II. But in the end, the Nazi narrative's defects contributed to its eventual failure.

\subsection{Answering and Learning from "Who?"}

During the prospect or presence of failure successful management likely generally requires properly motivated and informed subordinates. Managers and reports are symbiotically interdependent. This connection always has and will exist. In fact:

\section{- Without subordinates, neither management nor importantly, successful management through failure, can exist.}

Ironically, managers often lead as if they were ignorant of this reality. Yet successful managers always face an imperative to develop successful subordinates. But most managers also face another imperative - the need to develop a particular type of community: Who is this unit or organization? Answer properly, and managers may forge an "identity construction" for reports. Whether the identity emerges through respect for the manager or organization, fear of the manager or competitive threat, or individual pride/financial incentives matters little. What matters, instead, is that such a community, and associated identity, exists in the first place.

Once developed, community identity provides a touchstone with which subordinates can identify and rally around in times of crisis or challenge. The constructed identity should exemplify values subordinates will struggle to preserve or attain. Identities should substantiate standards of performance or behaviors to which employees feel an affiliation. An identity should provide a wellspring from which the follower community can draw practical insights, strategic direction, and even strength during challenging times - times of actual or potential failure.

Regardless of the managerial context, the ability to successfully construct a unit identity is related to movement. At their core, such movements entail motivating subordinates to mobilize in one or another direction. To some degree, the success with which managers lead employees though the inevitable opportunities to fail depends on the effectiveness with which they mobilize the unit as community.

Such communities can be real or imagined. Ironically, imagined communities can be stronger and more influential than their counterparts. One such community (i.e., Green Bay "Cheeseheads") lives and dies each autumn Sunday because of imagined affiliations each has forged with the Green Bay Packer football team. Of equal significance, is the affiliation "Cheeseheads" meld with their peers. That these peers bond more with each other, i.e., the unit, than with the idealized team is hardly surprising.

Many managers plainly believe in the potential power of a more objective (i.e., realistic) community identity. And have acted upon their belief. Historical examples exist in which community identities have emerged from leaders' creative responses to the "Who?" questions, and the persuasiveness with which those solutions were delivered. Abraham Lincoln must have understood how incredible power can materialize from a carefully conceived community identity. Wills (1992) singled out the Gettysburg Address as a supreme example of a community identity construction. Wills described how, on the occasion of the battle's first anniversary, Lincoln used only 272 words to rupture and rearrange an entire nation. Lincoln created a new identity for an existing community that transmogrified into - for the first time - a truly United States

The meaning of the words delivered at Gettysburg were embedded inextricably in the past, the present, and a presumably (better) future of America. With admirable brevity, Lincoln explained "Who America once was"; "Who America was then" (in 1864); and "Who America hopes to be" (one day). Lincoln's address was a persuasive managerial performance targeted at and entirely appropriate to a specific time and place.

To answer "Who?" effectively, managers aspiring to lead through failure must understand the right words must be tied to the right context at the right time. Outcomes in the contemporary world often pivot on the financial exchange nexus. In business, nothing happens until someone makes and markets, and someone else buys something - be it product, service, idea, person or conviction. The output of work itself has economic value, and money will surely drag any employee to work. At basic levels, money can mobilize subordinates.

But money is not guaranteed to inspire people to work harder, smarter or with greater focus. Rarer still would be occasions where money alone could inspire the formation of a collective identity for entire units. Moreover, money seldom functions as an effective mobilizer of effort at extreme edges, where wringing success from failure depends upon the unit's willingness to plan and execute decisions demanding professional risk or exceptional effort. Such 
maximal motivation is more often associated with the identity of a manager-lead unit, and the symbiotic relationship connecting managers and reports. Whether they face failure's threat or reality, managers who ignore the critical nature of managerial-subordinate relationships and the shared community identity that should emerge from those relationships do so at their own peril.

\subsection{Answering and Learning from "Why?"}

Successful management, executed during the prospect or presence of failure, requires learned persuasiveness. And when managers act persuasively in ways that benefit their firm, they rightfully expect to benefit. But most successful managers understand they should never "sell" any idea to anyone by explaining to prospects how much they - as persuaders - will benefit. Such an approach would be irrational. The risk of failure would heighten tremendously, regardless of the appeal of the persuader's value proposition.

All managers must engage, at least occasionally, in persuasive efforts. Many of their persuasive endeavors are internally focused - targeted at subordinates. The purpose of these persuasive efforts often follows from desires to motivate those employees and to mobilize their efforts toward one or another direction.

To be persuasive, managers must successfully answer the "Why?" question, i.e., "why do you 'subordinates' need to do this?" Whether this question is ever explicitly directed to managers by subordinates is of little concern. Managers still must answer it - in an acceptable fashion - in order to persuade (and manage) successfully. This imperative to do this grows whenever failure's prospect or reality looms.

Successful leaders tend to provide more persuasive; i.e., superior, answers to this "Why" question. Clearly, an ability to communicate internal messages effectively is a key to effective management. Successful managers are often masters of the art of persuasion. Thus, it is ironic that:

\section{- Many managers attempting to persuade followers to mobilize against failure threatening the welfare of their unit without reference to the opportunities, rationales, or needs of the entire community to which managers and subordinates each belong.}

When managers call for extra or more focused effort from subordinates based on organizational needs, rather than basing the call on "followers" needs, and little positive response follows, should anyone be surprised? In such situations, the missing ingredient may be an appeal from management aimed at persuading subordinates to take whatever actions are necessary to secure a better failure-free future for everyone in the organization. Even when times are good, successful management doesn't come easy. By definition, leading in the presence or prospect of failure is more challenging. In truly taxing times, successful managers may need to ignite the collective imagination of their unit's collective identity. In doing this, managers must mobilize subordinates to seek - and take ownership of - their own future destinations. To achieve such mobilization, managers must develop the requisite vision necessary to drive their unit's members from a "bad (or, at least, challenging) here" toward a "more appealing there" (in effect, more fully explicating the manager's answer to the "What?" question). Doing that, however, requires a persuasive answer to "Why?"

Typically, a full measure of employee motivation can be mobilized only through the essentially theatrically persuasive performances that characterize the most successful leaders. Successful leaders tend to perform so persuasively that the performance ensures followers will be sufficiently motivated to work sufficiently hard to get there - wherever "there" might lead.

The personal motivations of Dr. Martin Luther King and Adolf Hitler could hardly differ more. But as leaders and managers their ability to motivate followers through their powerful rhetorical and negotiating skills was astounding. Each man "owned" a strategic vision that proved highly effective as a mobilizer of followers in their respective contexts. Each demonstrated the ability and courage to deliver this vision persuasively. Finally, Dr. King and Adolf Hitler evinced the ability to deploy their visions through skillful negotiation. And in order to lead successfully through failure's inevitability, each man had to exhibit those persuasive abilities continuously. King did - to his untimely end. Hitler did not - and his end could not have arrived quickly enough.

For Dr. King, the "more appealing there" entailed the need for followers to inspire followers to move from the back of the bus (the past) to the front of the bus (the present) to eventual ownership of the bus (an esteemed future). To this day, King's "there" continues to motivate and inspire. For Hitler, the "more appealing there" constructed for his followers quickly led to an altogether different destination. Another lesson appears. The moral appropriateness of the "there" constructed by managers for subordinates also apparently matters a great deal. 
Managers might logically assume that persuasive efforts should be grounded in rational thinking and sensible execution. Yet genuinely inspiring leadership is more typically grooved, fundamentally, into a suitable emotional and symbolic lexicon. Such a lexicon surely includes the right words. But persuasive performances delivered by masters of the art of leading through failure, like Dr. King, moved beyond words.

Dr. King's "I Have a Dream" performance mobilized an entire nation. Nearly 50 years later it inspires movements. Consistent with precedent established by Lincoln at Gettysburg, King's performance persuaded through adroit reference to a distinctively American past, present, and future. "I Have a Dream" mobilized through its emotional delivery and symbolic dexterity. The performance coincided with the ministerial qualities of the man who delivered it. The performance meshed, essentially symphonically, with the context in which it was delivered. King's persuasive leadership performance was congruent with the emotions and symbols associated with its time and place. Even for individuals leading less momentous movements in challenging times, the lesson is clear.

- Logic is a necessary precursor to persuasion, and to successful management. But an exclusive reliance on logical argument often fails to mobilize followers to initiate and execute the extremely challenging courses of action that often prove necessary to push business units forward through the threat or reality of failure.

Imagine a setting where an entire unit (managers and subordinates alike) agree with a logical premise that it should operate lean. Such efficiencies ensure effectiveness that sustains or promotes the welfare of largest possible numbers of employees. But when the same logic requires that some of those same people be eliminated, logic often fails - for both managers and subordinates. When the subjects are persuasion and the art of applying history's lessons about failure, logic is surely necessary. Yet ironically, an exclusive reliance on logical persuasion often proves insufficient in the face of failure. Managerial success in this particular "persuasive" endeavor would likely require an inventive, as well as logical, strategic vision.

McLuhan's 1960's seminal insight that the "medium is the message" still applies. Indeed, his original truth has been amplified by the steroidal effects of Internet-driven media. Prior cultural eras shaped by the printed word often valued logic and reason more than today's workforce. Today, what is said often matters less than how it is said. Consequently, more emotional tribal-like appeals may become the communication calling cards of those who prove most capable of persuasively pushing subordinates through failure and toward success.

\section{A Management-Subordinate Paradox}

"Four brave men who do not know each other will not dare to attack a lion. Yet three ordinary men, knowing each other well, confident in their leader, assured of the reliability of all and consequently of mutual aid, will attack resolutely" - Ardant du Pieg

The more one learns about managing failure, the more contradictory the conclusions that one might logically gather seemingly become. This contradiction ensues in part from the Socratic paradox that the more one learns about any complicated subject, the more the extent of one's relative ignorance is revealed to the learner. Another cause follows from the subject's complexity. Myriad controllable and uncontrollable variables (i.e., manager and employee traits, situational and contextual issues, and interactions between each) must be evaluated to establish what counts as or contributes to successful business leadership. Moreover, successful management of failure in various situations demands different leadership styles. It is difficult to devise empirical studies yielding conclusive evidence on managing through failure because so many factors in interacting.

But realistically, should things differ? Leadership is always as much art as science. Inevitably, regardless of context, successful leadership is often only coincidentally about managers themselves. Yet ironically, successful management and leadership may be the only two factors common to all successful organizations. In successful firms, someone must assume responsibility for ensuring that the direction in which the firm's constituent parts are moving secures the interests and support of a critical business core. In such settings, managerial/subordinate relationships often unfold in ritualistic patterns of exchange that each group probably requires - despite mutual grumbling to the contrary.

Leadership failures are commonplace and well-known. That such failures have existed literally throughout modern business history underscores how inevitable failure is across contexts. History also reveals other insights applicable to the art of applying the lessons of failure. One of the most telling follows from the observation that:

- One factor consistently distinguishing successful from less successful business leaders may be whether their followers elected to save them from their own mistakes. 
Most managers often fail - falling short of anyone's ideal. So do most leaders - regardless of where, how or who they lead. Winston Churchill had Gallipoli; John Kennedy, the Bay of Pigs; Bill Clinton, Monica-gate. But each survived these failures to lead successfully through other struggles. To a substantial degree, each leader survived because followers elected to "save" them from their errors. Churchill and Clinton went on to lead successfully through other struggles, encounter still other failures (inescapability so), and receive more necessary assistance from followers. (Kennedy had his leadership opportunity cut so short that similar analogies cannot be drawn.)

For successful leaders, such follower interventions are hardly the exception. Instead, such intervention may well prove the rule. Napoleon, of course, had Waterloo. History fails to record any significant follower intervention on his behalf before, during, or after the battle of Waterloo. While Napoleon physically survived his Waterloo, his imperial movement and leadership opportunity did not.

Another lesson from the history of failure becomes evident, one that promises great profit to managers who apply it: Unless they are led through methods encouraging, enabling, and persuading them to do so, subordinates are less likely to deflect blame from, pick-up-the- pieces-after, or just-say-no to managers. Yet the opportunity to lead from just such an approach lies within most managers' grasp. Simply stop valuing people who reflexively say "yes' over those who tell it like it is - even though the latter group is more challenging to deal with in the short run.

Consequently, many managers who fail to apply the lessons of failure come up short unnecessarily. Many managerial failures therefore might be described as "voluntary"- virtually self-inflicted - in nature. That is because, ironically, many leaders fail to realize that:

\section{- Many organizational failures result not so much because of what managers do, but because of what subordinates permit them to get away with.}

Again, we find that managers must build the right sort of organizational community in order to increase the likelihood they will be manage through failure successfully. Thereafter, when failure or its prospect arrives managers should be able to tap into their organizational community's "inventiveness" by listening to and acting based on its constructive criticisms and suggestions. Many managers may presume what they do almost exclusively determines the success or failure of the firms they lead. Since what employees do or don't do substantially influences the success or failure of any organization, a final irony emerges:

\section{- Often, the most successful leaders are those who develop the least compliant followers.}

When leaders of organizations populated primarily by compliant employees encounter failure, fewer, if any, subordinates will be willing (or informed enough) to step up and make necessary corrective recommendations to their managers. Anyone remember Enron? Conversely, managers who make mistakes that can be and are addressed or even resolved by less compliant (more willing and enabled) employees are far more likely to succeed. Again, recalling where a primary source of power for most managers resides appears instructive. Often, that power resides within the "imagination" of their employees. Not coincidentally, this is where the "inventiveness" of employees also dwells. Managers should never mistake the "inventiveness" of individual employees as a threat. Instead, this inventiveness should be received as the opportunity it is - something to be cultivated, tapped into, and used to address problems that cannot be resolved by managers themselves.

Note, anecdotally, that more than occasionally, simply to survive, much less succeed when poised on the brink of failure, Captain Kirk needed Mr. Spock. Similarly, Batman needed Robin, or the Lone Ranger, Tonto. They heeded their advice, too. Such examples may appear facetious. But noting how noncompliant and inventive these three "followers" actually were is instructive. By knowing "someone had their backs," Kirk, Batman, and the Lone Ranger gained an enticing leadership advantage. Each gained the opportunity to lead openly and take additional measured risks.

This article began with reference to a war against cancer. As it ends referencing other warriors - a unit that understands occasional failure is inevitable - is therefore appropriate. The United States Marine Corps (U.S.M.C.) models its strategic planning and tactical execution on the quotation used to introduce this section. U.S.M.C. Officers lead, fight, and prevail by tapping the unique source of power that materializes whenever leaders and followers alike act in full "assurance of mutual aid." Corps officers do so as a matter of principle and precept. In the U.S.M.C. "someone always has your back" (Krulak 1997). Not surprisingly, never in its history has the Corps encountered an opportunity to fail that was not, in due time, turned to its advantage. Ironically, socialist author Walter Lippmann recognized the same phenomenon, writing: "The final test of a leader is that he leaves behind him in other men the conviction and will to carry on." 
Clearly, the ability to apply lessons learned from the myriad opportunities to fail that managers and firms inevitably encounter derives substantially from the skill with which managers develop strategically-noncompliant communities. The development of such a cohort surely must represent one of any successful managers' most significant "inventions." If nothing else, the presence of the cohort would keep managers on their toes. Beyond that, noncompliant followers intrinsically should be better prepared to help resolve problems that business leaders have caused or cannot resolve on their own. But subordinates cannot be expected to initiate ameliorative actions unless those behaviors are condoned by the prevailing organizational culture.

In this regard, two final guidelines appear relevant. To begin with, noncompliant managers will more likely "step in for" or "pick up after" managers under conditions when, in the doing, they understand they would be rewarded appropriately. This is clear. What is less clear is that noncompliant subordinates ideally should provide such assistance absent much fanfare. To this end, subordinates should be acculturated to understand that their own occasional failures need not result automatically in calls for their heads. After all, new managers would undoubtedly find themselves in similar situations. Consequently, managers should never "invent" organizational cultures that reward and thus facilitate obsequious follower-ship. Can there be any doubt why dictators - whose managerial style, by definition, promotes servile subordinates - fail in the end?

Authentic leaders should never be permitted to rightfully proclaim that since no subordinates were against them with respect to the answers given to the unit's "Who?" and "What? Questions, all must have been for them. The reason is simple: in the grand scheme of leadership, a failure to develop noncompliant followers is not an option. Lord Byron understood this. Revealingly, he wrote: "Where we think we lead, typically we are most led."

\section{References}

Anderson, B. S. (1991). Imagined Communities: Reflections on the Origin and Spread of Nationalism. London: Verso.

Groopman, J. (1998). “The Healing Hell.” The New Yorker. October 19, 34-38.

Jabri, W. (1996). Discourses on Violence: Conflict Analysis Reconsidered. Manchester: Manchester University Press.

Krulak, C.C. (1997). “A Synopsis of MCDP 1-3 Tactics.” [Online] Available: www.2ndbnmar.com.

Manz, C. C. (2002). The Power of Failure. San Francisco: Berret-Koehler Publishers, Inc.

The Random House College Dictionary. (2012). The Random House College Dictionary. New York: Random House.

Wills, G. (1992). Lincoln at Gettysburg. New York: Touchstone Press.

Note 1. The definition of failure used here is taken from Charles Manz (2002). Failure was defined as "a short-term unexpected result that reflects a challenge to progress that provides (1) a stepping stone to success, (2) an opportunity for learning and development, and (3) an opportunity to achieve creative change." Only one change - albeit a significant one - was made to Manz's definition. It is that failure should be received as a result to be expected - at least occasionally - and thus should be managed as productively as possible. Notably, Lao Tzu wrote: "Failure should not be feared. Failure, instead, is the foundation of success, and the means by which it is achieved." 
- "Successfully Leading Subordinates through Failure"

\section{Method 1: Answering WHAT?}

Provide an Answer to the Unit's "WHAT? Question - "What do we need to achieve [to earn a more desirable future]?"

Purpose associated with answering "What?" - To Inspire (Subordinates/Followers)

Answering WHAT Requires - An "Inventive Vision"

Successful managerial leadership in the face of failure requires inventiveness.

\section{Method 2: Answering WHO?}

Provide an Answer to the Unit's "WHO?" Question - “Who are we?”

Purpose associated with answering "Who?" - To Unify (Subordinates/Followers) Answering WHO Requires - An "Identify Construction"

Successful leadership in the face of failure requires properly motivated followers

\section{Method 3: Answering WHY?}

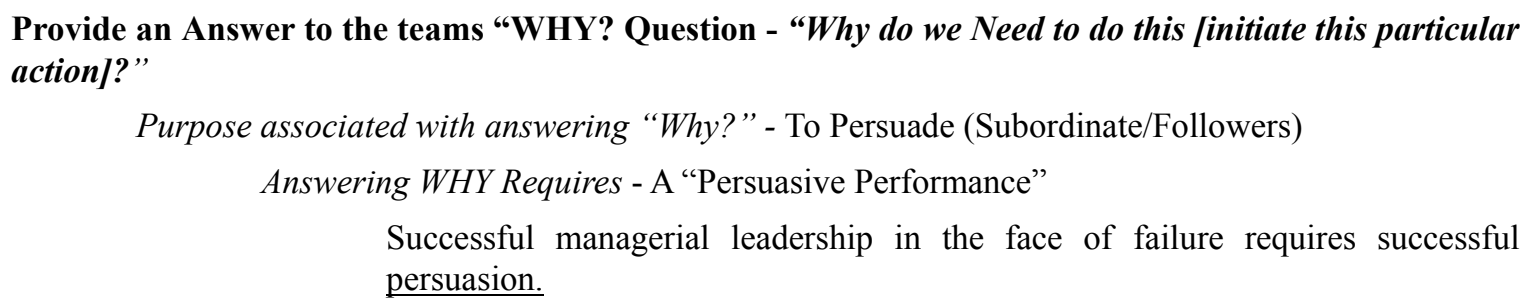

Figure 1. Three-Stage Methodology 